EDITORIAL

\title{
PESQUISA E INOVAÇÃO: O ESTADO DA ARTE
}

\section{Atson Carlos de Souza Fernandes}

Autor para correspondência: Atson Carlos de Souza Fernandes - atsonfernandes@bahiana.edu.br

Doutor em Ciências Morfológicas pela UNIFESP. Pró-reitor de pesquisa e inovação da Escola Bahiana de

Medicina e Saúde Pública. Professor Titular da Universidade do Estado da Bahia

No cenário mundial contemporâneo ciência, tecnologia e inovação (C,T\&l) tornaram-se marca registrada dos países com capacidade de desenvolvimento, crescimento econômico e geração de emprego e renda'. O domínio e a capacidade de aplicação do conhecimento científico no setor produtivo tem ampliado as oportunidades de investimento e crescimento, determinadas a partir da geração de novos produtos, processos, serviços e formas de organização, permitindo a muitas nações - protagonismo das decisões e implementação de estratégias inovadoras que atendam às demandas locais, regionais ou mesmo globais.

No Brasil, apesar da nossa franca expansão na pesquisa e pós-graduação, a exemplo do marco em ciência e tecnologia a partir da criação do Conselho Nacional de Desenvolvimento Científico e Tecnológico - CNPq (Lei $\left.{ }^{\circ} 1.310 / 1951\right)$ e da Coordenação de Aperfeiçoamento de Pessoal de Nível Superior - CAPES (Decreto $n^{\circ} 29.741 / 1951$ ) e surgimento do Ministério de Ciência e Tecnologia (MCT) no ano de 1985, só recentemente começouse a amadurecer uma política mais consistente de crescimento econômico, sustentabilidade e inclusão social a partir do conhecimento científico.

Desde o início do século XIX a Universidade de Berlim passou a incorporar a pesquisa no seu portfólio de atividades. Mais tarde, no final desse mesmo século, muitas universidades também adicionaram às suas funções atividades de pesquisa, fenômeno este que passou a ser conhecido como Primeira Revolução Acadêmica. A partir da criação do Massachusetts Institute of Technology (MIT), em 1862, iniciou-se um outro movimento que seria mais tarde adotado pelas demais universidades - a missão de contribuir para o desenvolvimento econômico e social. Esse segundo fenômeno passou a se chamar Segunda Revolução Acadêmica².

A partir de então, as universidades passaram a marcar a trajetória de desenvolvimento em muitos países. Nos Estados Unidos da América, onde as universidades são consideradas elementos estratégicos para $\circ$ desenvolvimento econômico e tecnológico do país ${ }^{3}$, o investimento de fundos para a pesquisa universitária e $\circ$ estreitamento das relações das universidades com a indústria permitiram sua franca recuperação da economia após a Segunda Guerra Mundial, bem como uma posição de liderança entre as potências mundiais ${ }^{4}$.

Em pleno século XXI, o principal desafio das Instituições Científicas e Tecnológicas (ICT) é promover o desenvolvimento de pesquisas visando não apenas a produção de conhecimento, mas também sua aplicação para geração de produtos ou processos com potencial de proteção intelectual, impacto social e desenvolvimento econômico. Apesar do Brasil atualmente ocupar posição de destaque no ranking mundial de produção científica ${ }^{5}$, sua 
capacidade de desenvolvimento tecnológico e inovação ainda é incipiente.

A cultura institucional da pesquisa aplicada com foco em resultados práticos para a solução de problemas é essencial para a inovação. A inovação, porém, muitas vezes resulta do empenho colaborativo de setores de pesquisa e desenvolvimento (P\&D) interagindo na fronteira do conhecimento. Diferentemente de invenção, que se trata de uma ideia ou modelo para um novo ou melhorado produto, processo ou sistema ${ }^{6}$, inovação, conforme definido na Lei 13.243, de 11 de janeiro de 2016, é a "introdução de novidade ou aperfeiçoamento no ambiente produtivo e social que resulte em novos produtos, serviços ou processos ou que compreenda a agregação de novas funcionalidades ou características a produto, serviço ou processo já existente que possa resultar em melhorias e em efetivo ganho de qualidade ou desempenho".

Nesse contexto, dada a importância para o desenvolvimento tecnológico, econômico e social do Brasil, foi publicada a Lei Federal $N^{\circ} 13.243$, de 11 de janeiro de 2016, também conhecida nos círculos de seus operadores como Marco Legal de Ciência, Tecnologia e Inovação, que "dispõe sobre estímulos ao desenvolvimento científico, à pesquisa, à capacitação científica e tecnológica e à inovação". Essa Lei busca incentivar parcerias estratégicas e o desenvolvimento de projetos de cooperação entre a academia e as empresas, sendo aquela uma fonte rica de informação e capacitação para o desenvolvimento de novas tecnologias que, transferidas para o setor produtivo, promoverão o desenvolvimento de produtos, processos e serviços inovadores ${ }^{8}$.

Para isso, entretanto, é necessário maior participação e interação do setor empresarial promovendo esforços para o desenvolvimento do país. Enquanto países em pleno desenvolvimento tecnológico como Estados Unidos, Alemanha, China, Coréia e Japão o setor empresarial é responsável pelo investimento de 70\% nos gastos de P\&D, no Brasil apenas se investe $45 \%$. Quanto maior a participação do setor empresarial nos esforços tecnológicos do país, maior será sua competitividade nos mercados nacional e internacional, com efeito direto na economia e redução das desigualdades sociais?.

Outro aspecto importante a ser considerado nesse panorama de ciência, tecnologia e inovação é a introdução do modelo de educação empreendedora na formação acadêmico-profissional. Nessa nova relação academia-empresa, gestores, pesquisadores e estudantes precisam estar preparados para extrapolar os "muros" da universidade e estreitar laços com os setores produtivos, organismos públicos e a própria sociedade, buscando e/ou sabendo reconhecer as oportunidades de parceria.

Ademais, a ciência tem evoluído e exigido cada vez mais profissionalismo de todos que interagem nesse ecossistema de desenvolvimento e sustentabilidade. Pesquisadores e instituições precisam estar preparados para o novo. Estamos na era da pesquisa de qualidade, impacto e relevância, do desenvolvimento tecnológico, da proteção de propriedade intelectual, da transferência de tecnologias, do surgimento de empresas dedicadas à exploração de novas ideias (startups e spin-offs), da inovação e da transformação social.

\section{REFERÊNCIAS}

1. Brasil. Ministério da Ciência e Tecnologia. PACTI - Plano de Ação 2007-2010: Ciência, Tecnologia e Inovação para o Desenvolvimento Nacional. Brasília. DF. 2010

2. Etzkowitz H. Research groups as "quase-firms": the invention of the entrepreneurial university. Research Policy. 2003;32(1):109-121

\section{Amadei JRP, Torkomian ALV. As patentes nas} universidades: análise dos depósitos das universidades públicas paulistas. Ci. Inf. 2009;38(2):9-18. doi: $10.1590 /$ S0100-19652009000200001

4. Mowery DC, Rosenberb N. Trajetórias da inovação: a mudança tecnológica nos Estados Unidos da América no século $X X$.

Campinas: Editora da UNICAMP; 2005. P. 230

5. Brasil. Ministério de Ciência e Tecnologia. Portal Brasil. Brasil está entre 25 primeiros lugares no ranking de artigos científicos. 2015. [Acesso em 27 nov. 2016]. Disponível em: <http://www.brasil.gov.br/ciencia-etecnologia/2015/06/brasil-esta-entre-25-primeiroslugares-no-ranking-de-artigos-cientificos> 
6. Schumpeter JA. Teoria do desenvolvimento econômico: uma investigação sobre o lucros, capital, crédito, juros e o ciclo econômico. São Paulo: Nova Cultural; 1988

7. Brasil. Lei 13.243/2016, de 11 de janeiro de 2016. Dispõe sobre estímulos ao desenvolvimento científico, à pesquisa, à capacitação científica e tecnológica e à inovação. Brasília. DF. 2016

8. Garnica LA, Torkomian ALV. Gestão de tecnologia em universidades: uma análise do patenteamento e dos fatores de dificuldade e de apoio à transferência de tecnologia no Estado de São Paulo. Gestão \& Produção. 2009;1 6(4):624-639. doi: 10.1590/S0104$530 \times 2009000400011$

9. Brasil. Ministério da Ciência, Tecnologia e Inovação. ENCTI - Estratégia Nacional de Ciência, Tecnologia e Inovação 2012-2015. Brasília. DF. 2012 